\title{
Bases epistemológicas de pesquisas relacionadas à população negra e educação
}

\author{
Epistemological basis of research on black population and education
}

\section{Bases epistemológicas de inuestigaciones asociadas a población negra y educación}

\section{Maria da Conceição Reis}

Universidade Federal de Pernambuco, Departamento de Administração Escolar e Planejamento Educacional do Centro de Educação, Professora Adjunta. https://orcid.org/0000-0001-5447-5069

\section{Claudilene Maria da Silva ${ }^{2}$}

Universidade de Integração Internacional da Lusofonia Afro-Brasileira, Professora. https://orcid.org/0000-0003-1015-1251

Resumo: Concebendo epistemologia como as formas de chegar ao conhecimento e às racionalidades que legitimam o conhecimento produzido, nesse trabalho consideramos como bases epistemológicas as teorias, as metodologias e os autores que fundamentam as pesquisas em educação. Nos interessa, objetivamente, identificar as bases epistemológicas que fundamentam pesquisas relacionadas à população negra e educação, refletindo os avanços e desafios epistemológicos frente ao pensamento hegemônico na produção acadêmica do Programa de PósGraduação em Educação da Universidade Federal de Pernambuco (PPGEdu/UFPE) no período de 2010-2020. 0 procedimento metodológico foi o levantamento bibliográfico. Exploramos dissertações e teses em educação inseridas no repositório digital da UFPE. 0 critério básico para a seleção dos trabalhos foi a identificação de temas relacionados à população negra. Observamos os títulos das produções, as palavras-chave e os resumos, através dos descritores: raça, racismo, discriminação racial, relações étnico-raciais, população negra, manifestações culturais negras e educação. Encontramos e analisamos 20 pesquisas defendidas e publicadas nos últimos dez anos, entre elas, 12 dissertações e 8 teses. Para apreender as bases epistemológicas das pesquisas, realizamos a leitura dos capítulos teórico-metodológicos. 0s resultados apontam que a produção acadêmica do PPGEdu-UFPE, no que se refere a aspectos da vida, da história e da cultura da população negra e das relações raciais no Brasil, embora ainda de forma incipiente, 
apresenta rasuras epistemológicas que revelam um conhecimento de ruptura com a hegemonia do pensamento eurocêntrico.

Palavras-chave: Base Epistemológica. Pesquisa. Conhecimento. População Negra. Educação e Relações Raciais.

Abstract: Conceiving epistemology as the ways of reaching knowledge and the rationalities that legitimize the produced knowledge, in this work we consider epistemological bases as the theories, methodologies and authors that support research on education. We are interested, objectively, in identifying the epistemological bases that support research related to the black population and education, reflecting the advances and epistemological challenges facing hegemonic thinking in the academic production of the Post Graduation Program in Education at the Federal University of Pernambuco (PPGEdu / UPPE) in 20102020 period. The methodological procedure was a bibliographic survey. The dissertations and theses in education, inserted in UPPE's digital repository, were researched by us. The basic criterion for the selected works was the identification of themes related to the black population. The titles, keywords and abstracts of the works were observed through the descriptors: race, racism, racial discrimination, ethnic-racial relations, black population, black cultural manifestations and education. Twenty researches defended and published in the last ten years were found and analyzed, including 12 dissertations and 8 theses. The epistemological bases of the research were learned by reading the theoretical-methodological chapters. The results show that the academic production of PPGEdu-UFPE, regarding aspects of life, history and culture of the black population and racial relations in Brazil, although still in an incipient way, presents epistemological erasures that reveal a knowledge of break with the Eurocentric thinking's hegemony. Keywords: Epistemological basis. Search. Knowledge. Black population. Education and Race Relations.

Resumen: Entendiendo epistemología como las formas de llegar al conocimiento y como las racionalidades que legitiman el conocimiento producido, en este trabajo consideramos como bases epistemológicas las teorías, las metodologías y los autores que fundamentan las investigaciones en educación. Nos interesa, objetivamente, identificar las bases epistemológicas que fundamentan investigaciones asociadas a población negra y educación, reflexionando sobre los avances y los desafios epistemológicos frente al pensamiento hegemónico, en la producción académica del Programa de Posgrado en Educación de la Universidad Federal de Pernambuco (PPGEdu/UFPE), en el período 2010-2020. El procedimiento metodológico fue la revisión bibliográfica. Exploramos tesis de maestría y doctorado en educación, contempladas en el archivo digital de la UFPE. El criterio básico para la selección de los trabajos fue la identificación de temas relacionados a la población negra. Tuvimos en cuenta los títulos de las producciones, las palabras clave y los resúmenes, a través de los descriptores: raza, racismo, discriminación racial, relaciones étnico-raciales, población negra, manifestaciones culturales negras y educación. Encontramos y analizamos 20 investigaciones sustentadas y publicadas en los últimos diez años, componiéndose este total de 12 tesis de maestría y 08 de doctorado. Para aprehender las bases epistemológicas de las investigaciones, realizamos la lectura de los capítulos teórico-metodológicos. Los resultados sugieren que la producción académica del PPGEdu/UFPE, en lo que se refiere a aspectos 
de la vida, la historia y la cultura de la población negra, así como de las relaciones raciales en Brasil, - aunque todavía de forma incipiente - presenta grietas epistemológicas que revelan un conocimiento de ruptura con la hegemonía del pensamiento eurocéntrico.

Palabras-clave: Base Epistemológica. Investigación. Conocimiento. Población Negra. Educación y Relaciones Raciales.

Recebido em 14 de setenbro de 2020

Aceito em 22 de março de 2021

\section{INTRODUÇÃO}

Até muito recentemente, a população negra brasileira não era considerada como sujeito político e de conhecimento. Desse modo, o processo de produção de saberes sobre o povo negro o colocava num lugar de objeto ou mero informante do processo investigativo. Inclusive, como aponta Sueli Carneiro (2005), em alguns momentos desqualificando a resistência negra pelo apelo à racialidade enquanto fator de subordinação e exclusão social. Ao discutir essa objetivação do negro, a autora afirma que assistimos:

\footnotetext{
a partir do final do século XIX um crescente processo de objetivação do negro nas ciências sociais no Brasil. Inicialmente impulsionado pela antropologia, os estudos sobre o negro avançaram para as relações raciais, e mais recentemente, para as desigualdades raciais envolvendo diversas disciplinas, passando contemporaneamente a um campo de disputa também de emergentes intelectuais e ativistas negros. (CARNEIRO, 2005 p. 59).
}

Assim, no campo da pesquisa científica, de forma sistemática, é somente a partir dos últimos 40 anos que a população negra começa a passar de objeto a sujeito de investigação. Todavia, existe uma vasta produção cultural e intelectual da autoria dos mais variados grupos sociais de maioria negra que foi desconsiderada ao longo da história do Brasil.

$\mathrm{Na}$ área da educação, autoras e autores (Gomes (2010); Cunha Junior (2006), entre outras e outros) afirmam que a produção científica que tematiza aspectos da vida e da educação da população negra ganha amplitude e articulação, a partir dos anos 2000 (embora encontremos trabalhos que datam dos anos 1980), com a criação da Associação Brasileira de Pesquisadores Negros (ABPN), e mais especificamente, com a constituição do Grupo de Trabalho Educação e Relações Étnico-Raciais - GT 21, da Associação Nacional de Pós-Graduação e Pesquisa em Educação (ANPEd). Conforme aponta Gomes (2010), as ações realizadas por ativistas, entidades ou organizações vinculadas ao movimento negro para 
inserção de negras e negros na universidade la exemplo dos cursinhos pré-vestibulares para negros e carentes e dos concursos de fomento à pesquisa), assim como a efervescência da discussão e a implementação das políticas de ações afirmativas no Brasil, impulsionam a presença de estudantes e docentes negras e negros nas universidades.

De acordo com Nilma Gomes (2010, p. 493):

A inserção de negros e negras no campo da pesquisa científica e da produção do conhecimento, não mais como objetos de estudo, mas como sujeitos que possuem e produzem conhecimento, faz parte da história de lutas sociais em prol do direito à educação e ao conhecimento, assim como da luta pela superação do racismo.

Para a autora, esses e outros pesquisadores oriundos de diferentes grupos sociais e étnicos, ao se inserirem nas universidades, desencadeiam um outro tipo de produção do conhecimento, um conhecimento realizado 'por' esses sujeitos, que privilegia a parceria 'com' os movimentos sociais ao invés de produzir conhecimento 'sobre' esses movimentos e seus sujeitos.

Contudo, ao analisarmos os estudos que se preocupam com as singularidades da vida e da cultura do povo negro no Brasil, percebemos que as teorias, e à perspectiva epistêmica da abordagem do problema, que orientam as análises e as interpretações, ainda é um aspecto que necessita ser mais aprofundado (SILVA, 2019). De acordo com Cunha Júnior (2006), os/as pesquisadores/as negros/as interessados/as em temas específicos da população negra podem ser agrupados em três tendências conceituais. Quais sejam: aquelas e aqueles que se abrigam nos conceitos weberiano e americanos de raça e raça social; aquelas e aqueles que seguem a tendência nacional de uma tentativa de composição entre raça social e classe social; e aquelas e aqueles que estão procurando a produção de um conhecimento de ruptura com a hegemonia do pensamento eurocêntrico.

0 presente trabalho nasce do diálogo entre duas professoras e pesquisadoras negras, cujos percursos de formação acadêmica foi vivenciado no Programa de PósGraduação em Educação (PPGEdu) da Universidade Federal de Pernambuco (UPPE) e que, por caminhos diferenciados, têm buscado contribuir com a produção desse conhecimento de ruptura da hegemonia do pensamento eurocêntrico.

A publicação de Santiago, Silva e Silva (2010) discute as questões raciais como objeto de pesquisa em educação no PPGEdu/UFPE e apresenta as pesquisas realizadas no período entre 1999 e 2009, marco de 10 anos da emergência da temática, quando o programa de pós-graduação celebrava 30 anos de existência. No capítulo introdutório, Santiago e Batista 
Neto (2010) refletem sobre o lugar dessa produção no programa, que no período identificado possuía somente 11 dissertações defendidas que versavam sobre a temática.

Apontando as exigências legais que demandam mudanças curriculares, Santiago e Batista Neto (2010) identificam limites e possibilidades para ampliação da inserção da temática. Por sua vez, também destacam as contribuições da produção acadêmica naqueles 10 anos de pesquisa ressaltando que: "as temáticas, os estudos bibliográficos e os procedimentos metodológicos dizem da sua atualidade, da importância social e da relevância acadêmica da produção do Programa e do esforço docente-discente no trato ao conhecimento e na aproximação com a realidade." (SANTIAGO; BATISTA NETO, 2010, p. 26).

0 estudo ora apresentado vem dar continuidade a essa produção a partir do período subsequente a 2010 até agosto de 2020, data final na qual coletamos informações para a produção dos dados da pesquisa. Entretanto, além de conhecer a relação das pesquisas realizadas no período e suas temáticas, nos interessa identificar as bases epistemológicas que sustentam as investigações discutindo as possibilidades de rasurar o eurocentrismo acadêmico.

Sem a pretensão de realizar julgamento de valor e concebendo a inexistência de epistemologias puras, nosso desejo é colaborar com a visibilidade, produção, invenção/reinvenção de perspectivas epistemológicas contra hegemônicas de produzir conhecimento. Compreendemos que este é um passo fundante no processo de desestabilização das relações, das estruturas, das condições e dos dispositivos de poder que mantêm a racialização, a inferiorização, a discriminação e a desigualdade da população negra, inclusive no âmbito educacional.

Assim, as questões elencadas para esta pesquisa foram: Que bases epistemológicas fundamentam as pesquisas relacionadas à população negra e educação no Programa de Pós-Graduação em Educação (PPGEdu) da Universidade Federal de Pernambuco (UFPE)? Que avanços e desafios epistemológicos revelam essas pesquisas frente ao pensamento hegemônico nas produções acadêmicas?

Nosso pressuposto é que, ao estudar as temáticas referentes à população negra no campo da educação, autoras/es e orientadoras/es influenciadas e influenciados pelo aumento de pesquisas no Brasil que fazem crítica à hegemonia eurocêntrica na educação, buscam possibilidades de bases epistemológicas diferentes das predominantes. Contudo, esbarram na insegurança e na falta de conhecimento aprofundado de outras epistemologias, ou autoras e autores que fazer o enfrentamento ao que está posto como única verdade ou caminho.

Reis, Lima e Nascimento (2019) destacam que a hegemonia do eurocentrismo embasando as pesquisas no Brasil vem desde o surgimento da pós-graduação neste país, década de 1930, e de sua regulamentação em nível nacional no ano de 1965 inspirada por vários fatores, dentre eles: "a presença estrangeira e os modelos educacionais praticados nos Estados Unidos (EUA) e na França” (REIS; LIMA; NASCIMENTO, 2019, p. 121) e que esses 
aspectos dificultam os autoras/es e orientadoras/es pesquisadoras/es de livrar-se dessas amarras que fizeram e continuam fazendo parte de sua formação.

Em busca das respostas às questões propostas, definimos como objetivo identificar as bases epistemológicas que fundamentam pesquisas relacionadas à população negra e educação refletindo os avanços e desafios epistemológicos frente ao pensamento hegemônico na produção acadêmica do PPGEdu/UFPE no período de 2010-2020.

Para o desenvolvimento do estudo faremos uma discussão teórica sobre epistemologia. Partimos da contribuição de Santos e Meneses (2010), para os quais epistemologia diz respeito às formas de chegar ao conhecimento e as racionalidades que validam o conhecimento produzido. Alinhadas a esse pensamento, neste trabalho consideramos como bases epistemológicas as teorias, as metodologias e os autores que fundamentam as pesquisas desenvolvidas no Programa de Pós-Graduação em Educação (PPGEdu) da Universidade Federal de Pernambuco (UFPE) sobre aspectos da vida e da cultura da população negra no Brasil. Nos interessa, especificamente, identificar os fundamentos que orientam as escolhas e guiam os modos de fazer pesquisa no campo da educação em sua interface com os aspectos citados.

0 procedimento metodológico foi o levantamento bibliográfico e o critério básico para a seleção dos trabalhos foi a identificação de temas relacionados à população negra, através dos descritores: raça, racismo, antirracismo, etnia, discriminação racial, étnico-racial/ is, negro/a, afro, Lei $n^{\circ} 10.639 / 2003$ e Lei $n^{\circ} 11.645 / 2008$. Durante a busca, encontramos mais três pesquisas que não apresentavam os descritores citados, mas tinham relação direta com a história e cultura afro-brasileira apresentando as seguintes palavras-chave: quilombola, candomblé e capoeira. Também encontramos palavras-chave, como samba e rastafari que nos chamaram atenção, mas os trabalhos estavam focados nos estudos sobre a educação popular, não discutindo os aspectos específicos relacionados à população negra.

Observamos os títulos das investigações, as palavras-chave e os resumos. Quando não encontramos a informação sobre as bases epistemológicas das pesquisas precisamente no resumo, realizamos a busca das palavras-chave em todo o texto, seguida pela leitura da introdução e dos capítulos teóricos e teórico-metodológicos. Para a organização e análise dos dados, adotamos a Análise de Conteúdo (AC) na perspectiva de Laurence Bardin (2011).

0 artigo foi organizado em três sessões: a seguir, discutiremos sobre a categoria epistemologia e sua relação com os estudos que tematizam as relações raciais, apresentaremos as bases epistemológicas das pesquisas relacionadas à população negra e educação no PPGEdu/UFPE no período de 2010-2020, para finalmente apontar, como resultado, que a produção acadêmica do PPGEdu-UFPE, no que se refere a aspectos da vida, da história e da cultura da população negra e das relações raciais no Brasil - embora ainda de forma 
incipiente - apresenta rasuras epistemológicas, que revelam um conhecimento de ruptura com a hegemonia do pensamento eurocêntrico.

\section{EPISTEMOLOGIA E ESTUDOS SOBRE RELAÇÕES RACIAIS}

Na intenção de apresentar pesquisas sobre população negra e educação e suas epistemologias, desenvolvemos a seguir o que estamos chamando de bases epistemológicas, destacamos a relação dessas bases, suas correntes e teorias, a partir da crítica ao eurocentrismo acadêmico, e finalizamos nossa discussão teórica apontando as perspectivas epistemológicas que direcionam um olhar central para os estudos sobre a população negra, com ela e dela.

\subsection{EPISTEMOLOGIA, BASES EPISTEMOLÓGICAS E EUROCENTRISMO ACADÊMICO}

0 desenvolvimento de uma pesquisa acadêmica possui algumas regras de cunho científico que exigem de pesquisadoras e pesquisadores uma tomada de posição. Uma delas é a definição de seu arcabouço teórico e teórico-metodológico. 0 olhar ou as lentes com as quais enxergamos e compreendemos a realidade é o que orienta nossas escolhas referentes ao modo de produção, à compreensão e às análises dos dados a respeito do seu objeto de estudo. Estamos chamando de bases epistemológicas a todo esse arcabouço. Não se trata de uma teoria, ou de um método ou de uma teórica ou teórico de referência, mas a concepção de ciência que orienta nossas escolhas sobre esse conjunto de elementos e as racionalidades que legitimam a validade do conhecimento produzido.

0 eurocentrismo, definido como a "interpretação da realidade a partir da perspectiva ocidental" (MAZAMA, 2009), até muito recentemente, era a única interpretação da realidade considerada como válida (para algumas pessoas ainda permanece). Todavia, os questionamentos e as reflexões realizadas em torno das promessas não cumpridas pela modernidade, bem como a repercussão desse desencantamento, colocam em xeque a eficiência de um modelo único de ciência no campo das ciências humanas e sociais em geral, e no campo da educação em particular (SILVA, 2019).

A hegemonia do eurocentrismo acadêmico não é um fato isolado ou descolado das relações sociais e históricas. A emergência do capitalismo como padrão de poder mundial e a 
dominação colonial europeia ou da Europa Ocidental sobre as diversas populações mundiais possibilitou que esse território se forjasse como o centro e medida de todas as coisas. Hierarquizando os povos, suas culturas e suas racionalidades, inferiorizou, subalternizou e desumanizou todas as pessoas e grupos não europeus. Para Quijano (2005 p. 121), "como parte do novo padrão de poder mundial, a Europa também concentrou sob sua hegemonia o controle de todas as formas de controle da subjetividade, da cultura, e em especial do conhecimento, da produção do conhecimento." Transformando sua experiência local em padrão universal, negou e invisibilizou todas as outras culturas e formas de existência.

Os Estudos Pós-Coloniais Latino-Americanos conceituam como colonialidade do saber o fato do conhecimento europeu ser considerado como única perspectiva de conhecimento reconhecido como válido, e a exclusão da existência e da viabilidade de outra racionalidade epistêmica e outros conhecimentos que não aqueles produzidos pela racionalidade moderna e pelos homens brancos europeus ou europeizados (WALSH, 2008). Ancorados na perspectiva decolonial, consideram que as racionalidades epistêmicas não europeias, foram invisibilizadas, mas não deixaram de existir.

Nesse sentido, a perspectiva eurocêntrica de produção de conhecimento já não pode mais ser vista como única possibilidade válida de conhecimento. De acordo com Sousa Santos e Meneses: "toda experiência social produz e reproduz conhecimento, e ao fazêlo, pressupõe uma ou várias epistemologias." (SANTOS; MENESES, 2010 p. 15). Para ambos, o conhecimento é produzido no interior das relações sociais, de forma que diferentes tipos de relações sociais podem dar origem a diferentes epistemologias. Assim, epistemologia "é toda a noção ou ideia, refletida ou não, sobre as condições do que conta como conhecimento válido." (SANTOS; MENESES, 2010 p. 15).

Para Tello (2012), a perspectiva e a posição epistemológicas, entre outros, são componentes necessários em uma pesquisa. A perspectiva epistemológica é considerada "a visão de mundo que o pesquisador assume para orientar a pesquisa." (TELLO, 2012, p. 57, tradução nossa). 0 autor cita como exemplo: "marxismo, neomarxismo, estruturalismo, pós-estruturalimo, existencialismo, humanismo, positivismo e pluralismo." (TELL0, 2012, p. 57, tradução nossa). Por sua vez, o posicionamento epistemológico está vinculado às correntes teóricas da própria perspectiva epistemológica.

Neste caso, o pesquisador assume um posicionamento a partir de visão de mundo, a partir de como compreende a cosmovisão - como lê, como constrói a realidade "em termos de refletividade epistemológica. Nesse sentido, o posicionamento epistemológico passa a ser o posicionamento político do pesquisador." (TELL0, 2012, p. 57, tradução nossa). Alguns exemplos apresentados: construtivismo político, complexidade, ecletismo, pós-moderno, neoliberal, transformativo, funcionalista, crítico, crítico radical, crítico-analítico, teórico da resistência e humanístico. 
0 autor não nega que posições epistemológicas e perspectivas epistemológicas se misturam nas pesquisas, pois é comum que pesquisadoras e pesquisadores possam fazer combinações e relações entre perspectiva epistemológica e posicionamentos. Mas chama atenção que a vigilância epistemológica é uma atitude que deve estar sempre presente nas pesquisadoras e pesquisadores.

Conforme aponta Quijano (2009), a perspectiva eurocêntrica, em qualquer de suas variantes - seja o liberalismo ou o materialismo histórico, o estruturalismo, o estruturalismofuncionalista, o funcionalismo ou mesmo a modernidade - não abarcam as questões de subjetividades e de gênero na configuração do poder. Concebem a existência social das pessoas configuradas por elementos historicamente homogêneos e consistentes que guardam entre si relações contínuas, lineares e unidirecionais.

Ancorados na afrocentricidade Césaire (2010), Mazama (2009) e Nascimento (2008, 2009), chamam a atenção para que pesquisadoras e pesquisadores revejam a imagem de inferiorização do continente africano propagadas por inúmeros pensadores referendados nas ciências humanas eurocêntricas aliadas ao paradigma civilizatório, enquanto "saberes e práticas compartilhadas por um grupo de pessoas, e que transcende os limites geográficos onde vivem, que dão vivacidade e organização a um modo de observar, agir e compreender o mundo" (ALVES; JESUS; SCHOLZ, 2015).

No mesmo caminho trilhado por Tello (2012), outros estudos (LOPES, 2013; MAINARDES; FERREIRA; TELLO, 2011) ajuda-nos a entender e conhecer as bases epistemológicas, os posicionamentos, as teorias e suas origens. Importante destacar que uma perspectiva surge na intenção de resolver as limitações encontradas em perspectivas anteriores consolidadas no mundo acadêmico. Estas, necessariamente, não deixam de existir para que uma outra apareça. 0 que acontece é que, ao ser questionada, sua influência nas pesquisas vai dando lugar a outras possibilidades e sua hegemonia vai sendo abalada.

A seguir, refletimos sobre como esse percurso vem acontecendo nas pesquisas e nas perspectivas epistemológicas dos estudos que tematizam as relações raciais e a história e cultura da população negra no Brasil.

\subsection{ESTUDO DAS RELAÇÕES RACIAIS E POSIÇÕES EPISTEMOLÓGICAS}

Os estudos de Guimarães (2018) mostram que uma tradição de estudos em relações raciais forjou-se no Brasil desde o final do século XIX. Essa tradição que foi interrompida com o golpe militar de 1964, fazendo com que o tema sofresse uma interdição, passando a ocupar um 
lugar marginal na academia. Todavia, retornou aos poucos após a redemocratização do Brasil e se intensificou com as politicas de ação afirmativa nas primeiras décadas dos anos 2000 .

Os primeiros estudiosos da questão racial, à época, o problema do negro, comungavam a ideia de supremacia branca. Silvio Romero e Nina Rodrigues, podem ser considerados seus expoentes. Argumentavam em suas análises sobre o negro brasileiro que estes possuíam uma inferioridade inata. De acordo com Carneiro (2005, p. 60):

\footnotetext{
Durante o século XX assiste-se à proliferação de institutos de pesquisas, centros de estudos africanos ou de relações raciais em todo $\circ$ pais, que titularam e tornaram célebres pesquisadores e intelectuais brancos especialistas em "negro". [...] Saberes e instituições apropriadas por brancos, conformando além de interpretações, modos de subjetivação para o negro.
}

Othando para as ciências sociais e, especificamente, para a reprodução da desigualdade socioeconômica entre grupos raciais, Osório (2008) realiza um balanço das teorias que orientam estes trabalhos e identifica três ondas teóricas. Afirma, entretanto, que o início de uma onda teórica não significa o fim ou superação da anterior. Pelo contrário, cada uma sobreviveu após o surgimento da sua sucessora, permanecendo até a atualidade.

A primeira onda fundamenta-se na ideia de que no Brasil existia o preconceito de classe sem preconceito racial. Tem em Gilberto Freyre sua maior representatividade, mas Donald Pierson, Arthur Ramos, Thales de Azevedo e Charles Wagley são outros nomes de destaque. A miscigenação e democracia racial são suas bases teóricas. De acordo com Osório (2008, p. 74): "o fato de que havia mestiços entre as elites econômicas e políticas, ou desempenhando - com reconhecimento social - ocupações prestigiosas, era tido como sinal de ausência de preconceito racial." 0 legado da escravidão, sua proximidade histórica, é apontado como a causa da situação socioeconômica dos negros.

A segunda onda, forjada nos estudos patrocinados pelo Projeto UNESCO, afirma a realidade e a especificidade do preconceito racial no Brasil. Para Osório (2008), em que pese sua heterogeneidade, o que une os representantes dessa onda é a crença de que o preconceito racial existe e tem uma especificidade, que é só pode ser entendido a luz da história e do regime escravista. Assim, perderia sua funcionalidade e se tornaria elemento arcaico e irracional, uma herança do passado. Florestan Fernandes, Roger Bastide, Oracy Nogueira e Luiz Costa Pinto são apontados como os principais representantes dessa onda, na qual também são incluídos Otávio lanni e Fernando Henrique Cardoso. Afirma Osório (2008) que é o trabalho de Fernandes que define os contornos da segunda onda. Para Fernandes, "o racismo e o preconceito racial surgem durante o Brasil Colônia para cumprir uma função de legitimação da ordem social, e tende a desaparecer com a transição para a sociedade de 
classes." (OSÓRI0, 2008 p. 81). A raça perderia relevância na sociedade por conta do processo de modernização em função do desenvolvimento capitalista. A explicação classista é o traço comum entre os autores das duas primeiras ondas.

A terceira onda preocupa-se com medir os efeitos do preconceito racial. Inicia-se no final dos anos de 1970 com os trabalhos de Carlos Hasenbalg e Nelson do Valle Silva, teses de doutorado defendidas em 1978 nos Estados Unidos. Ambos os trabalhos usam técnicas estatísticas sofisticadas e mostram que "os negros tendiam a permanecer na mesma posição relativamente subalterna de seus pais, a despeito de sua incorporação à moderna sociedade de classes." (OSÓRI0, 2008 p. 86). Logo, racismo, preconceito e discriminação racial são persistentes, duradouros e tendem a se perpetuar na perspectiva de manutenção dos privilégios das elites brancas.

Em seu trabalho, Guimarães (2018 p. 27) evidencia o surgimento de uma quarta onda no limiar do século XXI (ainda não teorizada), ao afirmar que "uma profusão de dissertações, teses e artigos ocorreu a partir de então, impulsionando não apenas o debate acadêmico, mas também fornecendo elementos para a intervenção política do Movimento Negro." Para o autor, com o advento dos programas e projetos de Ações Afirmativas e das formulações das Políticas de Promoção da lgualdade Racial, ganham destaque trabalhos que se fundamentam na terceira onda, mas que dela se diferenciam, uma vez que não permanecem nem na análise das relações raciais, nem no diagnóstico das desigualdades raciais. Concentrados na área da sociologia e da educação, tais pesquisas focalizam experiências de promoção da igualdade racial, não se encaixando, portanto, no rótulo de "relações raciais", mas sim de "políticas raciais" (GUIMARÃES, 2018, p. 28).

Olhando para o campo da educação, o estudo de Reis, Lima e Nascimento (2019), identificou que o acesso de pesquisadores negros e negras militantes e ativistas provocou rasuras epistemológicas na pós-graduação proporcionando novas possibilidades de conhecimento e ruptura com a hegemonia do pensamento eurocêntrico. Segundo Mazama (2003, p. 11):

\footnotetext{
Não se pode entender o que está acontecendo ao nosso redor e com a gente, pelo menos nos últimos quinhentos anos se não reconhecer 0 papel racial branco de dominar o mundo, isto é, a supremacia branca [...] a crença na superioridade branca é acompanhada pelo projeto para garantir ao branco, em virtude de sua superioridade, controlar o mundo.
}

Para a autora, a referida supremacia branca se faz presente nas bases epistemológicas de perspectiva europeia e vem sendo questionada no mundo nos últimos anos. 
Ciente disso, Tello (2012) provoca a América Latina a assumir o desafio de construir suas próprias epistemologias. A perspectiva decolonial, nascida entre pesquisadoras e pesquisadores deste continente, defende que, para a superação das relações de dominação colonial simbólica e histórica, é preciso questionar os modelos de dominação e produzir novas epistemes (QUIJANO, 2009).

Asante (2014) e Mazama (2003, 2009) através da Afrocentricidade, provocam os pesquisadores a repensar o lugar da África e dos povos africanos da diáspora na ciência. Numa perspectiva afrocentrada, pesquisar sobre a população negra da diáspora requer conhecimento e afirmação da história e cultura africana a partir da "proposta epistemológica do lugar". Ou seja: "voltar e apanhar de novo aquilo que ficou para trás, aprender do passado." (NASCIMENTO, 2008, p. 31). A afrocentricidade, enquanto uma abordagem epistemológica inovadora, segue por caminhos que valorizam a natureza, a ancestralidade, a história, a origem, a cultura e a vida dos africanos do continente e da diáspora. Para Asante (2014, p. 14): "Afrocentricidade é a convicção de que o povo africano estará no centro da história pós-moderna. É nossa história, nossa mitologia, nossas ideias criativas e nossos ethos como expressão de nossa determinação coletiva."

Gomes (2017) revela a contribuição do movimento negro enquanto "produtor de saberes emancipatórios e de um sistematizador de conhecimentos sobre a questão racial no Brasil" (p. 14). Para a referida autora:

\footnotetext{
A compreensão dos saberes produzidos, articulados e sistematizados pelo Movimento Negro tem a capacidade de subverter a teoria educacional, construir a pedagogia das ausências e das emergências, repensar a escola, descolonizar os currículos. Ela poderá nos levar ao necessário movimento de descolonização do conhecimento. (GOMES, 2017, p. 139).
}

Ou seja, diferentemente da perspectiva positivista que prega a neutralidade do pesquisador, novos olhares epistemológicos pregam a tomada de posição políticoepistemológica para o desenvolvimento das pesquisas, ciente do que somos, onde estamos e do que queremos. Como ressaltado por Silva, Silva e Silva (2019, p. 1) “Os movimentos sociais, indígenas e negros, passam a apontar a necessidade de se repensar a educação para além do modelo eurocêntrico." Cada vez mais somos chamadas e chamados a assumir nossas origens e analisar os objetos de estudos com o olhar político, crítico e transformador. 


\section{POPULAÇÃO NEGRA E EDUCAÇÃO NO PPGEDU/UFPE (2010- 2020)}

0 levantamento das pesquisas relacionadas à população negra e educação no Programa de Pós-Graduação em Educação (PPGEdu) da Universidade Federal de Pernambuco (UFPE) foi realizado tendo como fonte o banco de dados da instituição, o site ATTENA Repositório Digital da UFPE.

Consideramos todas as dissertações e teses inseridas e publicadas no Repositório Digital, entre janeiro de 2010 e agosto de 2020. Encontramos seiscentas (600) pesquisas: 399 dissertações e 201 teses. E entre estas, passamos a delimitar as que interessava ao nosso estudo.

Nessa sessão apresentamos o resultado do levantamento encontrado em dois momentos. Primeiro, realizamos uma apresentação geral do conjunto dos trabalhos encontrados e, na sequência, discutimos as bases epistemológicas das pesquisas, foco deste artigo.

\subsection{PRODUÇÃO DO PPGEDU/UFPE RELACIONADA À POPULAÇÃO NEGRA E EDUCAÇÃO (2010-2020)}

A identificação da produção do PPGEdu/UFPE relacionada à população negra no conjunto dos trabalhos encontrados foi realizada a partir dos descritores pré-estabelecidos. Encontramos as seguintes palavras-chave: antirracismo, candomblé angola, capoeira, cultura africana, cultura afro-brasileira, cultura negras, danças afro-brasileiras, educação afrocêntrica, educação e desigualdades étnico-raciais, educação para as relações étnicoraciais, etnia negra, história e culturas afro-brasileira e indígena, identidade negra, identidades étnico-raciais, igualdade racial, juventude negra, Lei $n^{\circ} 10.639 / 2003$, negras, negros, quilombola, racismo institucional, racismo, relações étnicas-raciais e relações étnico-raciais.

No universo das seiscentas (600) pesquisas defendidas, considerando o período estabelecido, janeiro de 2010 a agosto de 2020, encontramos 20 pesquisas ( 12 dissertações e 8 teses) que versam sobre as relações raciais ou sobre aspectos da vida, da história ou da cultura da população negra em sua interface com a educação, como podemos visualizar na Tabela 1 a seguir: 
Tabela 1 - População Negra e Educação no PPGEdu/UFPE (2010-2020)

\begin{tabular}{|c|c|c|c|c|}
\hline \multirow{2}{*}{$\begin{array}{l}\text { ANO DE } \\
\text { DEFESA }\end{array}$} & \multicolumn{2}{|c|}{ TRABALHOS } & \multirow{2}{*}{$\begin{array}{c}\text { POPULAÇÃO } \\
\text { NEGRA }\end{array}$} & \multirow[b]{2}{*}{ AUTORIA } \\
\hline & (T) & (D) & & \\
\hline 2010 & 17 & 46 & 01 & Dayse Cabral de Moura (T) \\
\hline \multirow{4}{*}{2011} & \multirow{4}{*}{17} & \multirow{4}{*}{45} & \multirow{4}{*}{04} & Auxiliadora Maria Martins da Silva (T) \\
\hline & & & & Roseane Maria de Amorim (T) \\
\hline & & & & Adriana Ribeiro de Barros (D) \\
\hline & & & & Euclides Ferreira da Costa (D) \\
\hline \multirow{3}{*}{2012} & \multirow{3}{*}{20} & \multirow{3}{*}{27} & \multirow{3}{*}{03} & Henrique Gerson Kohl (T) \\
\hline & & & & Maria da Conceição dos Reis (T) \\
\hline & & & & Ana Cláudia Oliveira da Silva (D) \\
\hline 2013 & 07 & 56 & 00 & - \\
\hline 2014 & 16 & 32 & 00 & - \\
\hline \multirow{2}{*}{2015} & \multirow{2}{*}{19} & \multirow{2}{*}{49} & \multirow{2}{*}{02} & Maria da Conceição de C. Varejão Filha (D) \\
\hline & & & & Marco Aurélio Acioli Dantas (D) \\
\hline \multirow{2}{*}{2016} & \multirow{2}{*}{27} & \multirow{2}{*}{44} & \multirow{2}{*}{02} & Claudilene Maria da Silva (T) \\
\hline & & & & Edmilton Amaro da Hora Filho (D) \\
\hline \multirow{3}{*}{2017} & \multirow{3}{*}{28} & \multirow{3}{*}{48} & \multirow{3}{*}{03} & Delma Josefa da Silva (T) \\
\hline & & & & Emeline Apolonia de Melo (D) \\
\hline & & & & Juliana de Lima Barros (D) \\
\hline \multirow{5}{*}{2018} & \multirow{5}{*}{22} & \multirow{5}{*}{25} & \multirow{5}{*}{05} & Michele Guerreiro Ferreira (T) \\
\hline & & & & Cleiton Amâncio Félix (D) \\
\hline & & & & Camila Ferreira da Silva (D) \\
\hline & & & & Renildes de Jesus Silva de Oliveira (D) \\
\hline & & & & Pietro Manoel da Silva (D) \\
\hline 2019 & 27 & 26 & 00 & -- \\
\hline 2020 & 01 & 01 & 00 & - \\
\hline \multirow{2}{*}{ TOTAL } & & & & 08 - Teses (T) \\
\hline & 201 & 399 & 20 & 12 - Dissertações (D) \\
\hline
\end{tabular}

Fonte: os autores.

A leitura da tabela revela que 10 anos após o primeiro balanço sobre o lugar da temática racial no PPGEdu/UFPE, realizado por Santiago e Batista Neto (2010), não encontramos muitas alterações quantitativas.

Em 2009, havia 11 pesquisas de mestrado defendidas. A novidade para 2020 é a inserção das teses de doutorado. A primeira delas sendo defendida logo no ano seguinte, 2010. Em 2011 temos a defesa de quatro trabalhos, em 2012, três. Os dois próximos anos não registraram defesas. 2015 e 2016, dois trabalhos em cada ano. Novamente três defesas em 2017, para alcançar cinco trabalhos em 2018, e permanecer sem registros de defesa até agosto de 2020. 
Ou seja, quando olhamos o conjunto dos trabalhos ao longo dos 10 últimos anos, percebemos que a produção no Programa permanece quantitativamente inalterada - 12 dissertações e 8 teses. 20 trabalhos num universo de 600 pesquisas defendidas. Conforme observaram Santiago e Batista Neto (2010), a experiência do Programa permanece sem alterar a continuidade-descontinuidade das pesquisas relacionadas à temática. Contudo, tais pesquisas também permanecem possuindo atualidade, importância social e relevância acadêmica, como também foi destacado.

Apesar do pequeno número de trabalhos, as contribuições dessas pesquisas também permanecem sendo importantes para fomentar outros estudos e subsidiar outras pesquisadoras e pesquisadores que desejam investigar temáticas da educação relacionadas à população negra, sejam os aspectos da política e da prática curricular ou pedagógica, sejam os aspectos culturais relacionados a educação, os trabalhos aportam boas contribuições.

Como não é objetivo deste estudo fazer o estado da arte destas pesquisas, apresentamos de forma breve as temáticas do conjunto da produção. São trabalhos que tematizam a educação para as relações étnico-raciais, focando o currículo e a prática pedagógicas em diversos níveis e modalidades de ensino, a exemplo da educação básica, da educação superior, da modalidade de educação de jovens e adultos e da educação escolar quilombola. Alguns tematizam a educação em sua interface com manifestações culturais e religiosas, como a dança afro-brasileira, o maracatu, a capoeira e o Candomblé. Outros buscam dar conta da discussão mais teórica, como a sociogênese do conceito de etnia negra na educação; e ainda outros abarcam aspectos identitários, seja na história de vida de seus sujeitos, seja nas práticas escolares vivenciadas pelos sujeitos. Alguns ainda focalizam a educação de seguimentos específicos, como as mulheres negras e a juventude negra aprisionada.

Considerando o objetivo deste artigo, a seguir passamos a discutir as bases epistemológicas que fundamentam as referidas pesquisas.

\subsection{BASES EPISTEMOLÓGICAS DAS PESQUISAS RELACIONADAS À POPULAÇÃO NEGRA E EDUCAÇÃO NO PPGEDU/UFPE (2010- 2020)}

A identificação das bases epistemológicas foi realizada a partir da leitura dos resumos e dos capítulos introdutórios, teóricos e teórico-metodológicos, quando necessários. Consideramos como critério de identificação a declaração das pesquisadoras e pesquisadores sobre o arcabouço teórico e teórico-metodológico em seus trabalhos e agregamos as pesquisas encontradas em três grupos temáticos: 1) pesquisas de bases epistemológicas 
de origem europeia; 2) pesquisas de bases epistemológicas decoloniais e afrodiaspóricas; 3) pesquisas que não declaram as bases epistemológicas, mas apresentam autores como aporte teórico.

A partir dos agrupamentos, elaboramos quadros temáticos que foram compostos por duas colunas: a primeira com a identificação da pesquisa, onde constam - autora/autor, título, identificação de dissertação ou tese e o ano de defesa (definido como critério de apresentação no quadro); na segunda coluna consta a base epistemológica ou autores citados pela pesquisa, enquanto posicionamento epistemológico anunciado pela autora ou autor.

0 Quadro 1 apresenta dez pesquisas (cinco dissertações e cinco teses) que demarcaram sua posição epistemológica a partir de um arcabouço teórico-metodológico alinhado à perspectiva eurocêntrica. Vejamos:

Quadro 1 - Bases epistemológicas europeias nas pesquisas relacionadas à população negra no PPGEdu/UFPE (2010-2020)

\begin{tabular}{|l|l|}
\hline \multicolumn{1}{|c|}{ Identificação } & \multicolumn{1}{|c|}{ Bases/autores } \\
\hline $\begin{array}{l}\text { AMORIM, Roseane Maria. As práticas curriculares cotidianas: um estudo da educação } \\
\text { nas relaçães étnico-raciais na Rede Municipal do Recife. Tese de doutorado, 2011. }\end{array}$ & $\begin{array}{l}\text { Estudos Culturais e } \\
\text { Pós-estruturalismo }\end{array}$ \\
\hline $\begin{array}{l}\text { OLIVEIRA. Renildes de Jesus Silva. "O que é de Deus e o que não é de Deus": docentes } \\
\text { evangélicos e o ensino das culturas africanas afro-brasileiras nas escolas públicas. } \\
\text { Dissertação de mestrado, 2018. }\end{array}$ & $\begin{array}{l}\text { Pós-estruturalista e } \\
\text { Teoria do Discurso }\end{array}$ \\
\hline $\begin{array}{l}\text { MELO, Emeline Apolonia. Lei 11645/08: uma análise das práticas curriculares em uma } \\
\text { escola municipal do Recife desde o mito de Malunguinho. Dissertação de mestrado, } \\
\text { 2017. }\end{array}$ & Teoria do Discurso \\
\hline $\begin{array}{l}\text { SILVA, Pietro Manoel. Educação e identidade cultural afro-brasileira na cidade do Recife: } \\
\text { uma percepção do discurso afro em escolas municipais a partir do Programa de } \\
\text { Animação Cultural (2005-2008). Dissertação de mestrado, 2018. }\end{array}$ & Teoria do Discurso \\
\hline $\begin{array}{l}\text { MOURA, Dayse Cabral. Leitura e identidades étnico-raciais: reflexões sobre práticas } \\
\text { discursivas na educação de jovens e adultos. Tese de doutorado, 2010. }\end{array}$ & $\begin{array}{l}\text { Análise Crítica do } \\
\text { Discurso }\end{array}$ \\
\hline $\begin{array}{l}\text { KOHL, Henrique Gerson. Educação e capoeira: figuraçães emocionais na cidade do } \\
\text { Recife-Pernambuco-Brasil. Tese de doutorado, 2012. }\end{array}$ & Norbert Elias \\
\hline $\begin{array}{l}\text { SILVA, Auxiliadora Maria Martins. Sociogênese do conceito de etnia negra na educação } \\
\text { brasileira. Tese de doutorado, 2011. }\end{array}$ & Norbert Elias \\
\hline $\begin{array}{l}\text { REIS, Maria da Conceição. Educação, identidade e histórias de vidas de pessoas } \\
\text { negras do Brasil. Tese de doutorado, 2012. }\end{array}$ & Norbert Elias \\
\hline $\begin{array}{l}\text { FÉLIX, Cleiton Amâncio. Maracatu Leão de Ouro do Condado-PE brincar ou se apre- } \\
\text { sentar? Dissertação de mestrado, 2018. }\end{array}$ & $\begin{array}{l}\text { Perspectiva da } \\
\text { tradução cultural }\end{array}$ \\
\hline $\begin{array}{l}\text { HORA FLHO, Edmilton Amaro. Ecopedagogia no terreiro de Candomblé Angola. Disserta- } \\
\text { ção de mestrado, 2016. }\end{array}$ & $\begin{array}{l}\text { Teoria da } \\
\text { complexidade }\end{array}$ \\
\hline Fone: os a a
\end{tabular}

Fonte: os autores. 
As bases epistemológicas citadas são: Estudos Culturais, Pós-estruturalismo, Teoria do Discurso, Análise Crítica do Discurso, Perspectiva da tradução cultural, Teoria da complexidade e a Teoria Sociológica de Norbert Elias.

É possivel perceber a forte presença do pós-estruturalismo nessas pesquisas, embora apenas duas delas anunciem explicitamente em seus resumos. Quais sejam: Oliveira (2018) "fundamentado numa perspectiva pós-estruturalista, esse trabalho foi realizado a partir de um diálogo com alguns conceitos da Análise do Discurso Francesa, interpretada à luz da Teoria do Discurso de Laclau e Mouffe" e Amorim (2011) "0 estudo se insere no campo dos Estudos Culturais e do pós-estruturalismo".

Outras três pesquisas declaram apenas a partir da teoria do discurso e da análise crítica do discurso: Melo (2017) anuncia a perspectiva da Teoria do Discurso a partir de Ernesto Laclau; Silva (2018), que construiu sua dissertação abordando a categoria identidade na perspectiva definida por Stuart Hall, que se afilia aos estudos culturais e anuncia que seu "arcabouço teórico-metodológico passou respectivamente pela Teoria do Discurso (TD), elaborada por Ernesto Laclau e Chantal Mouffe." Por sua vez, Moura (2010) toma como "aporte teórico os estudos de Fairclough e dialoga com a "análise de discurso textualmente orientada (ADTO)".

Em seguida, temos três teses que se filiam a partir dos estudos de Norbert Elias: Silva (2011, p. 24) "Seguimos uma trajetória teórica orientada pela teoria de Elias [...] sobre o processo civilizador"; Kohl (2012) "tem-se uma tese com relevância educacional que se evidência, à luz da teoria eliasiana" e Reis (2012) "As ideias do autor Norbert Elias deram sustentação teórica [...] com as contribuiç̃̃es de Kabengele Munanga e Paulo Freire." Nesse caso, a autora anuncia o diálogo com outras perspectivas teóricas, que veremos no Quadro 2, referente às bases epistemológicas decoloniais e afrodiaspóricas.

As duas últimas pesquisas apresentadas no Quadro 1 têm especificidades diferenciadas. Nestes casos foi necessário ler mais do que o resumo para encontrar a posição epistemológica. Félix (2018, p. 12) discute sobre identidades culturais, na "perspectiva da tradução cultural aqui apontada nos postulados de Walter Benjamim, Derrida e Homi Bhabha" embora que esses autores, além de pós-estruturalistas, também podem ser identificados pela teoria crítica (Benjamim) e pós-colonial (Bhabha). Hora Filho (2016, p. 10) aborda a teoria da complexidade em diálogo com saberes da religiosidade: "abordamos a teoria da complexidade [...] os saberes da tradição apresentando as características da tradição do Candomblé."

Percebemos que, embora fundamentados na perspectiva eurocêntrica, alguns estudos tendem a buscar diálogos com outras perspectivas epistêmicas, quando seus objetos de investigação necessitam ser olhados, considerando outras possibilidades de 
conhecimento que não apenas o racional ou o cognoscivel. Aqui ocorre, notadamente, com pesquisas relacionadas a processos identitários, culturais e religiosos.

0 segundo grupo temático é apresentado no Quadro 2, referente às pesquisas relacionadas à população negra e educação, que tomam como base as perspectivas epistemológicas decoloniais e afrodiaspóricas. Encontramos quatro pesquisas (uma de mestrado e três de doutorado), como podemos conferir a seguir:

Quadro 2 - Bases epistemológicas decoloniais e afrodiaspóricas nas pesquisas relacionadas à população negra no PPGEdu/UFPE (2010-2020)

\begin{tabular}{|l|l|}
\hline \multicolumn{1}{|c|}{ Identificação } & \multicolumn{1}{|c|}{ Bases } \\
\hline $\begin{array}{l}\text { FERREIRA, Michele Guerreiro. Educação das relações étnico-raciais e prática curri- } \\
\text { cular de enfrentamento do racismo na UNILAB. Tese de doutorado, 2018. }\end{array}$ & $\begin{array}{l}\text { Pensamento Decolonial } \\
\text { e Perspectivas Pós- } \\
\text {-colonialistas de } \\
\text { Currículo. }\end{array}$ \\
\hline $\begin{array}{l}\text { SILVA, Camila Ferreira. As marcas da memória hegemônica e da memória vivida } \\
\text { nas imagens da mulher negra nos didáticos do território campesino do Brasil e da } \\
\text { Colômbia: um olhar através dos estudos pós-coloniais e do feminismo negro latino- } \\
\text {-americano. Dissertação de mestrado, 2018. }\end{array}$ & $\begin{array}{l}\text { Estudos Pós-coloniais } \\
\text { e Feminismo Negro } \\
\text { Latino-americano. }\end{array}$ \\
$\begin{array}{l}\text { SILVA, Delma Josefa. Referenciais epistêmicos que orientam e substanciam práticas } \\
\text { curriculares em uma escola localizada na comunidade quilombola de conceição das } \\
\text { crioulas. Tese de doutorado, 2017. }\end{array}$ & $\begin{array}{l}\text { Africanidades brasi- } \\
\text { leiras e Pensamento } \\
\text { decolonial latino- }\end{array}$ \\
\hline $\begin{array}{l}\text { SILVA, Claudilene Maria. Práticas pedagógicas de valorização da identidade, da } \\
\text { práticas de branqueamento. Tese de doutorado, 2016. }\end{array}$ & $\begin{array}{l}\text { Estudos Pós-Coloniais } \\
\text {-americano. }\end{array}$ \\
\hline
\end{tabular}

Fonte: os autores.

As autoras denominam suas bases de: Estudos Pós-Coloniais Latino-Americanos, Feminismo Negro Latino-americano. Pensamento Decolonial, Pensamento Decolonial LatinoAmericano, Pensamento Afrocêntrico, Afrocentricidade e Africanidades Brasileiras.

Identificamos pesquisas que assumem a posição política epistemológica anunciando apenas uma base ou em diálogo com outras perspectivas. Silva (2018) anuncia: "adotamos a teoria curricular pós-crítica na vertente pós-colonial de currículo, focando um currículo intercultural crítico"; e Ferreira (2018), que se coloca politicamente ao dizer: "Como opção política e epistêmica, adotamos como abordagem teórica o Pensamento Decolonial". As que anunciam o diálogo com outras perspectivas são: Silva (2017), "nossas lentes teóricasmetodológicas focam o pensamento afrocêntrico [...], as africanidades brasileiras [...] em 
diálogo com o pensamento decolonial latino-americano"; e Silva (2016), "assumimos os Estudos Pós-Coloniais Latino-Americanos como abordagem teórico-metodológica em diálogo com a Afrocentricidade como posição epistemológica."

Este é um agrupamento composto apenas por mulheres. E mulheres que se declaram e se apresentam em seus trabalhos de pesquisa como mulheres negras. Em conformidade com as bases epistemológicas por elas anunciadas, as autoras consideram a explicitação de seus lugares de enunciação e localização epistêmica como um elemento de rigor teórico-metodológico.

Embora realizando diálogos e composições com outras perspectivas, todas as pesquisas estão ancoradas nos Estudos Pós-Coloniais Latino-Americanos. Outro elemento comum a esses trabalhos é vinculação ao núcleo de pesquisa Formação de Professores e Práticas Pedagógicas. As autoras compartilharam uma formação comum e realizaram suas escolhas epistêmicas a partir das especificidades de seus objetos de investigação.

No Quadro 3 reunimos as pesquisas que não declaram as bases epistemológicas, mas apresentam autores como aporte teórico. Nesse grupo foram identificados os últimos seis trabalhos. Todos eles são pesquisas de mestrado, como é possível ver a seguir:

Quadro 3 - Estudos que apresentam autoras/es como aporte teórico nas pesquisas relacionadas à população negra no PPGEdu/UPPE (2010-2020)

\begin{tabular}{|c|c|}
\hline Identificação & Autores \\
\hline $\begin{array}{l}\text { BARROS, Juliana de Lima. Makena: a prática educativa de uma professora de } \\
\text { música em Jaboatão dos Guararapes e a educação das relações étnico-raciais. } \\
\text { Dissertação de mestrado, } 2017 \text {. }\end{array}$ & Paulo Freire. \\
\hline $\begin{array}{l}\text { COSTA, Euclides Ferreira. Juventude negra e a educação na prisão. } \\
\text { Dissertação de mestrado, } 2011 .\end{array}$ & $\begin{array}{l}\text { Michel Foucault e Paulo } \\
\text { Freire. }\end{array}$ \\
\hline $\begin{array}{l}\text { BARROS, Adriana Ribeiro. Trilhas e partilhas na prática pedagógica de dança Afro- } \\
\text {-brasileira. Dissertação de mestrado, } 2011 .\end{array}$ & Paulo Freire. \\
\hline $\begin{array}{l}\text { VAREJÃO FlLHA, Maria da Conceição de Carvalho. Prática Pedagógica Docente } \\
\text { Promotora de Igualdade Racial. Dissertação de mestrado, } 2015 .\end{array}$ & $\begin{array}{l}\text { Paulo Freire, Nilma } \\
\text { Gomes e Petronilha } \\
\text { Gonçalves Silva. }\end{array}$ \\
\hline $\begin{array}{l}\text { DANTAS, Marco Aurélio Acioli. Gestão escolar e Educação Para as Relações Étnico- } \\
\text {-Raciais na comunidade quilombola de Castainho. Dissertação de mestrado, } 2016 .\end{array}$ & $\begin{array}{l}\text { Kabengele Munanga, } \\
\text { Nilma Gomes e Petronilha } \\
\text { Gonçalves. }\end{array}$ \\
\hline $\begin{array}{l}\text { SILVA, Ana Cláudia Oliveira. Diversidades etnicorraciais e a política educacional } \\
\text { em Pernambuco: a inclusão da História e Cultura Afro-Brasileira e Indigena como } \\
\text { conteúdo curricular. Dissertação de mestrado, } 2012 \text {. }\end{array}$ & Nilma Gomes. \\
\hline
\end{tabular}

Fonte: os autores. 
$\mathrm{Na}$ leitura dos trabalhos desse agrupamento não encontramos o anúncio de suas bases epistemológicas: nem no resumo, nem na introdução ou nos capítulos teóricos ou metodológicos. Dessa forma, para não correr o risco de enquadrar inadequadamente as pesquisas, optamos por apresentá-las a partir das autoras e autores que compõem o aporte teórico para a discussão de suas as categorias conceituais.

Paulo Freire é encontrado em quatro pesquisas, embora apenas Barros (2017) anuncia que trata das relações étnicas-raciais e antirracismo fazendo uma "abordagem sobre a prática educativa na perspectiva freireana." Costa (2011, p. 48), ao pesquisar sobre a educação em prisão parte do olhar de Michel Foucault, entre outros, "seguindo as trilhas abertas por Freire." Barros (2011, p. 17) escreve que foi ao fixar "o olhar sobre o trabalho com a cultura brasileira na escola tomando a manifestação dança afro-brasileira como produção desta cultura" que se aproximou dos teóricos, entre eles Freire). Varejão Filha (2015) discute sobre igualdade racial e prática pedagógica apoiando-se em Freire para os estudos sobre prática docente.

No terceiro grupo temático também encontramos autoras e autores que são referências para os estudos sobre a temática população negra e educação, como Nilma Gomes, Petronilha Gonçalves Silva e Kabengele Munanga. Além de documentos legais, como as Diretrizes Curriculares Nacionais para a Educação das Relações Étnico-Raciais (DCN/ERER).

Varejão Filha (2015) anuncia que para discutir a "categoria igualdade racial, buscamos nos estudos de Gomes [...], Gonçalves e Silva, além das normativas legais." Dantas (2016, p. 34) cita Kabengele Munanga, Nilma Gomes e Petronilha Gonçalves Silva e ressalta: "recorremos às contribuições dos estudos da educação para as relações étnico-raciais, Diretrizes Curriculares Nacionais para a Educação das Relações Étnico-Raciais." Silva (2012) não indica suas referenciais teóricas, porém utiliza Gomes para discutir as categorias sobre as relações étnico-raciais.

Embora este grupo de trabalhos não anuncie suas bases epistemológicas, percebe-se por meio das autoras e autores identificados como referências, uma aproximação com perspectivas que buscam reconhecer e valorizar aspectos da vida, da história e da cultura da população negra no campo educativo.

\section{AUANÇOS E DESAFIOS EPISTEMOLÓGIICOS FRENTE AO PENSAMENTO HEGEMÔNICO}

Os dados revelaram que, em alguns casos, não foi possível identificar explicitamente no texto a identificação do posicionamento teórico e do enfoque epistemológico. Nesse modo, 
consideramos a existência de três características nas pesquisas, no que se refere às bases epistemológicas para a produção de conhecimento: a) pesquisas que demarcaram suas posições epistemológicas, utilizando expressões como: "Nos filiamos", "0 estudo se insere", "Como opção política e epistêmica"; b) pesquisa que utilizam referências de diversas autoras e autores, técnicas metodológicas, categorias analíticas e perspectivas epistemológicas que podem ter, ou não têm uma relação epistemológica; c) pesquisas que não explicitam a posição epistemológica das pesquisadoras e pesquisadores. Fato que em outros tempos poderia ser associado à neutralidade da pesquisa. Hoje, como sabemos essa neutralidade é impossível. Assim, acreditamos que este fato se relaciona mais com as dificuldades da pesquisadora ou pesquisador iniciante, o que impossibilita sua reflexão epistemológica.

A produção de conhecimento no campo da educação é uma produção de conhecimento do humano, com e/ou sobre humanos. E como não há neutralidade no mundo dos humanos - uma vez que somos movidos por interesses, necessidades e intenções diversas - explicitar os fundamentos e implicações do trabalho investigativo é um ato de rigor epistemológico cada vez mais necessário para legitimar o conhecimento produzido.

Finalmente, considerando o objetivo desse estudo, olhando o conjunto das pesquisas nesses dez últimos anos, no que diz respeito a origem das bases teóricas percebemos que são poucas as perspectivas epistêmicas que estão localizadas no sul global, e portanto, são consideradas teorias contra hegemônicas. Ainda há um predomínio das epistemologias dominantes (eurocêntricas), do norte global.

Todavia, o Quadro 2 nos leva a inferir que as pesquisas relacionadas à população negra e educação no PPGEed/UFPE podem seguir por outras possibilidades epistemológicas para além das eurocêntricas. 0 que revela, conforme constatado por Cunha Júnior (2006), que existem pesquisadoras e pesquisadores interessadas/os em romper com a hegemonia do pensamento eurocêntrico, proporcionando outros olhares para seus objetos de estudo referentes a população negra.

Os resultados apontam que a produção acadêmica do PPGEdu-UFPE, no que se refere a aspectos da vida, da história e da cultura da população negra e das relações raciais no Brasil- embora ainda de forma incipiente - apresenta rasuras necessárias que desestabiliza a hegemonia do pensamento eurocêntrico, revelando novas possibilidade de concepções epistemológicas.

Entretanto, ainda precisamos avançar na compreensão de que, ao assumir posicionamentos a partir de perspectivas epistemológicas que questionam os modelos de dominação, da subalternização e da pretensa supremacia branca, estamos contribuindo para superação do racismo e das desigualdades raciais no campo da educação. 
Consideramos que não se trata de encantar-se com modismos ou conceber as epistemologias contra hegemônicas como puras ou melhores que as demais. Compreendemos que elas são aquelas que melhor se adequam aos estudos que desejam colaborar com a rejeição da suposta inferioridade da população negra.

Questionar a hegemonia da perspectiva eurocêntrica não é negá-la, trata-se de reconhecer que tal forma de produção do conhecimento não é a única. Portanto, é visibilizar a existência de epistemologias que seguem caminhos direcionados ao reconhecimento da história, a valorização da cultura e o fortalecimento da ancestralidade do povo negro.

\section{REFERÊNCIAS}

ALVES, M. C.; JESUS, J. P.; SCHOLZ, D. Paradigma da afrocentricidade e uma nova concepção de humanidade em saúde coletiva: reflexões sobre a relação entre saúde mental e racismo. Saúde Debate, Rio de Janeiro, v. 39, n. 106, p. 869-880, jul./set. 2015.

AMORIM, R. M. As práticas curriculares cotidianas: um estudo da educação nas relações étnico-raciais na Rede Municipal do Recife. 2011. Tese (Doutorado em Educação) - Programa de Pós-Graduação em Educação, Universidade Federal de Pernambuco, Recife, 2011.

ASANTE, M. K. Afrocentricidade: a teoria de mudança social. Filadélfia: Afrocentricity Internacional, 2014.

BARDIN, L. Análise de conteúdo. Tradução: Luís Antero Reto e Augusto Pinheiro. São Paulo: Edições 70, 2011.

BARROS, A. R. Trilhas e partilhas na prática pedagógica de dança Afro-brasileira. 2011. Dissertação (Mestrado em Educação) - Programa de Pós-Graduação em Educação, Universidade Federal de Pernambuco, Recife, 2011.

BARROS, J. de L. Makena: a prática educativa de uma professora de música em Jaboatão dos Guararapes e a educação das relações étnico-raciais. 2017. Dissertação (Mestrado em Educação) Programa de Pós-Graduação em Educação, Universidade Federal de Pernambuco, Recife, 2017.

CARNEIRO, A. S. A construção do outro como não-ser como fundamento do ser. 2005. Tese (Doutorado em Educação/área de Filosofia da Educação) - Faculdade de Educação, Universidade de São Paulo, Recife, 2005.

CÉSAIRE, A. Discurso sobre o colonialismo. Tradução: Anísio Garcez Homem. IS. ll: Letras contemporâneas, 2010.

COSTA, E. F. Juventude negra e a educação na prisão. 2011. Dissertação (Mestrado em Educação) Programa de Pós-Graduação em Educação, Universidade Federal de Pernambuco, Recife, 2011. 
CUNHA JÚNIOR, H. Metodologia Afrodescendente de Pesquisa. Texto de Trabalho na disciplina de Educação Gênero e Etnia na perspectiva dos Afrodescendentes. [S. l.: s. n.], 2006. Disponível em: http:// afrobrasileira.multiply.com/journal/item/52?\&show_interstitial=1\&u=\%2Fjournal\%2Fitem. Acesso em: 5 abr. 2011.

DANTAS, M. A. A. Gestão escolar e educação para as relações étnico-raciais na comunidade quilombola de Castainho. 2016. Dissertação (Mestrado em Educação) - Programa de Pós-Graduação em Educação, Universidade Federal de Pernambuco, Recife, 2016.

FÉLIX, C. A. Maracatu Leão de Ouro do Condado-PE: brincar ou se apresentar? 2018. Dissertação (Mestrado em Educação) - Programa de Pós-Graduação em Educação, Universidade Federal de Pernambuco, Recife, 2018.

FERREIRA, M. G. Educação das relações étnico-raciais e prática curricular de enfrentamento do racismo na UNILAB. 2018. Tese (Doutorado em Educação) - Programa de Pós-Graduação em Educação, Universidade Federal de Pernambuco, Recife, 2018.

GOMES, N. L. Intelectuais negros e produção do conhecimento: algumas reflexões sobre a realidade brasileira. In: SANTOS, B. de S.; MENESES, M. P. (org.). Epistemologias do Sul. São Paulo: Cortez, 2010.

GOMES, N. L. 0 movimento negro educador: saberes construídos nas lutas por emancipação. Petrópolis, RJ: Vozes, 2017.

GUIMARÃES, C. A. S. Movimento negro e mudança institucional no brasil: políticas municipais de promoção da igualdade racial em perspectiva comparada (1995-2015). 2018. Tese (Doutorado em Ciência Política) - Instituto de Filosofia e Ciências Humanas, Universidade Estadual de Campinas, 2018.

HORA FLLHO, E. A. Ecopedagogia no terreiro de Candomblé Angola. 2016. Dissertação (Mestrado em Educação) - Programa de Pós-Graduação em Educação, Universidade Federal de Pernambuco, Recife, 2016.

KOHL, H. G. Educação e capoeira: figuraç̃̃es emocionais na cidade do Recife-Pernambuco-Brasil. 2012. Tese (Doutorado em Educação) - Programa de Pós-Graduação em Educação, Universidade Federal de Pernambuco, Recife, 2012.

LOPES, A.C. Teorias pós-críticas, politica e currículo. Educação, Sociedade \& Culturas, Porto: CllE, n. 39, p. 7-23, 2013. Dossiê temático: Configurações da Investigação Educacional no Brasil. Disponível em: http://www.fpce.up.pt/ciie/sites/default/files/02.AliceLopes.pdf. Acesso em: 23 ago. 2020.

MAINARDES, J.; FERREIRA, M. S. F.; TELLO, C. G. Análise de políticas: fundamentos e principais debates teórico-metodológicos. In: BALL, S. J.; MAINARDES, J. (org.). Políticas educacionais: questões e dilemas. São Paulo: [s. n.], 2011. p. 143-172.

MAZAMA, A. A afrocentricidade como um paradigma. In: NASCIMENTO, E. L. (org.). Afrocentricidade: uma abordagem epistemológica inovadora. São Paulo: Selo Negro, 2009. 
MAZAMA, A. L'Impératif Afrocentrique. Pennsylvania: Afrocentricity International, 2003.

MELO, E. A. Lei 11645/08: uma análise das práticas curriculares em uma escola municipal do Recife desde o mito de Malunguinho. 2017. Dissertação (Mestrado em Educação) - Programa de Pós-Graduação em Educação, Universidade Federal de Pernambuco, Recife, 2017.

MOURA, D. C. Leitura e identidades étnico-raciais: reflexões sobre práticas discursivas na educação de jovens e adultos. 2010. Tese (Doutorado em Educação) - Programa de Pós-Graduação em Educação, Universidade Federal de Pernambuco, Recife, 2010.

NASCIMENTO, E. L. (org.). Afrocentricidade: uma abordagem inovadora. São Paulo: Selo Negro, 2009.

NASCIMENTO, E. L. Sankofa: Significado e Intenções. In: NASCIMENTO, E. L. (org.). A matriz africana no mundo. São Paulo: Selo Negro, 2008.

OLIVEIRA. R. de J. S. "0 que é de Deus e o que não é de Deus": docentes evangélicos e o ensino das culturas africanas afro-brasileiras nas escolas públicas. 2018. Dissertação (Mestrado em Educação) Programa de Pós-Graduação em Educação, Universidade Federal de Pernambuco, Recife, 2018.

OSÓRIO, R. G. Desigualdade racial e mobilidade social no Brasil: um balanço das teorias. In: THEODORO, M. (org.). As políticas públicas e a desigualdade racial no Brasil: $१ 20$ anos após a abolição. Brasília, DF: lpea, 2008. p. 69-99.

QUIJANO, A. Colonialidade do poder e classificação social. In: SANTOS, B. S.; MENESES, M. P. (org.) Epistemologias do Sul. Coimbra: Almedina, 2009. p. 73-118.

QUIJANO, A. Colonialidade do poder, Eurocentrismo e América Latina. In: LANDER, E. (org.). A colonialidade do saber: eurocentrismo e ciências sociais: perspectivas latino-americanas. CLACSO, Buenos Aires: Argentina, 2005. p. 1-27. (Colección Sur Sur).

REIS, M. C.; LIMA, C. S.; NASCIMENTO, E. R. Reflexões sobre o paradigma afrocentrado na pós-graduação brasileira. Revista Sul-Americana de Filosofia e Educação, n. 31, p. 119-135. D0l: https://doi. org/10.26512/resafe.vi3128260.

REIS, M. da C. Educação, identidade e histórias de vidas de pessoas negras do Brasil. 2012. Tese (Doutorado em Educação) - Programa de Pós-Graduação em Educação, Universidade Federal de Pernambuco, Recife, 2012.

SANTIAGO, E; BATISTA NETO, J. As questões raciais como objeto de pesquisa em educação: PPGE/UFPE 1999-2009. In: SANTIAGO, E.; SLLVA, C.; SLVA, D. (org.). Educação, Escolarização e ldentidade Negra: dez anos de pesquisa sobre relações raciais no PPGE/UFPE. Recife: Editora Universitária da UFPE, 2010

SANTIAGO, E.; SILVA, C.; SILVA, D. (org.). Educação, Escolarização e ldentidade Negra: dez anos de pesquisa sobre relações raciais no PPGE/UFPE. Recife: Editora Universitária da UFPE, 2010. 
SANTOS, B. S.; MENESES, M. P. (org.). Epistemologias do Sul. São Paulo: Cortez, 2010.

SILVA, A. C. 0. Diversidades etnicorraciais e a política educacional em Pernambuco: a inclusão da História e Cultura Afro-Brasileira e Indígena como conteúdo curricular. 2012. Dissertação (Mestrado em Educação) - Programa de Pós-Graduação em Educação, Universidade Federal de Pernambuco, Recife, 2012.

SILVA, A. M. M. Sociogênese do conceito de etnia negra na educação brasileira. 2011. Tese (Doutorado em Educação) - Programa de Pós-Graduação em Educação, Universidade Federal de Pernambuco, Recife, 2011.

SILVA, C. A volta inversa na árvore do esquecimento e nas práticas de branqueamento: práticas pedagógicas escolares em história e cultura afro-brasileira. Curitiba: CRV, 2019.

SILVA, C. F. As marcas da memória hegemônica e da memória vivida nas imagens da mulher negra nos didáticos do território campesino do Brasil e da Colômbia: um olhar através dos estudos pós-coloniais e do feminismo negro latino-americano. 2018. Dissertação (Mestrado em Educação) - Programa de Pós-Graduação em Educação, Universidade Federal de Pernambuco, Recife, 2018.

SILVA, C. M. Práticas pedagógicas de valorização da identidade, da memória e da cultura negras: a volta inversa na árvore do esquecimento e nas práticas de branqueamento. 2016. Tese (Doutorado em Educação) - Programa de Pós-Graduação em Educação, Universidade Federal de Pernambuco, Recife, 2016.

SILVA, D. J. Referenciais epistêmicos que orientam e substanciam práticas curriculares em uma escola localizada na comunidade quilombola de conceição das crioulas. 2017. Tese (Doutorado em Educação) - Programa de Pós-Graduação em Educação, Universidade Federal de Pernambuco, Recife, 2017.

SILVA, J. B.; SILVA, E. F.; SLLVA, E. J. L. Educação e diferença: diálogos e perspectivas. Roteiro, Joaçaba, v. 44, n. 2, p. 1-6, maio/ago. 2019. D0l: https://doi.org/10.18593/r.v44i2.21524.

SILVA, P. M. Educação e identidade cultural afro-brasileira na cidade do Recife: uma percepção do discurso afro em escolas municipais a partir do Programa de Animação Cultural (2005-2008). 2018. Dissertação (Mestrado em Educação) - Programa de Pós-Graduação em Educação, Universidade Federal de Pernambuco, Recife, 2018.

TELLO, C. G. Las epistemologías de la política educativa: vigilancia y posicionamiento epistemológico del investigador en política educativa. Práxis Educativa, Ponta Grossa: Universidade Estadual de Ponta Grossa, v. 7, n. 1, p. 53-68, enero/jun. 2012.

VAREJÃO FlLHA, M. da C. de C. Prática Pedagógica Docente Promotora de lgualdade Racial. 2015. Dissertação (Mestrado em Educação) - Programa de Pós-Graduação em Educação, Universidade Federal de Pernambuco, Recife, 2015. 
WALSH, C. Interculturalidad, Plurinacionalidade y Decolonialidad: las insurgencias político-epistémicas de refundar el Estado. Revista Tabula Rasa, Bogotá, Colômbia, n. 9, p. 131-152, jul./dic. 2008.

Endereço para correspondência: Avenida Prof. Moraes Rego, 1235, Cidade Universitária, 50670-901, Recife, Pernambuco, Brasil; cecareis@hotmail.com 